River Research

and Applications

Flood Energy Dissipation in Anabranching Channels

\begin{tabular}{|r|l|}
\hline Journal: & River Research and Applications \\
\hline Manuscript ID & RRA-17-0223.R2 \\
\hline Wiley - Manuscript type: & Research Article \\
\hline Date Submitted by the Author: & 05-Apr-2018 \\
\hline Complete List of Authors: & $\begin{array}{l}\text { Entwistle, Neil; University of Salford, School of Environment and Life } \\
\text { Sciences } \\
\text { Heritage, George; AECOM, } \\
\text { Milan, David; University of Hull, School of Environmental Sciences }\end{array}$ \\
\hline Keywords: & Anabranching, LiDAR, Natural Flood Management, 2D hydraulic modelling \\
\hline
\end{tabular}

SCHOLARONEm

Manuscripts 


\title{
Flood Energy Dissipation in Anabranching Channels
}

\author{
Neil Entwistle ${ }^{1}$, George Heritage ${ }^{2}$, and David Milan*3 \\ ${ }^{1}$ School of Environment and Life Sciences, University of Salford, Peel Building, \\ Salford, M5 4WT, UK \\ ${ }^{2}$ AECOM, Exchange Court, 1 Dale Street, Liverpool, L2 2ET,UK \\ 3 *School of Environmental Science, University of Hull, Cottingham Road, Hull, HU6 \\ 7RX, UK, d.milan@hull.ac.uk
}


Keywords: Anabranching; LiDAR; natural flood management

\section{Abstract}

This study examines the character of developing anabranched channel networks on the River Wear, north England using metre-scale aerial LiDAR. DSM-DTM interpretation reveals a well-developed vegetation structure and a locally diverse terrain, dominated by an interlinked channel network split by low elevation depositional areas with the gross morphology of the reach resembling that of a strongly active meandering / wandering channel suggesting that an anabranching network may develop within systems that were initially active meandering and wandering, evolving in line with floodplain vegetative succession. Utilisation of the LiDAR DEM in the hydrological component of the CAESAR-Lisflood (version 1.4) morpho-dynamic model has generated local hydraulic variable estimates through the anabranched reaches for a range of flows. These data clearly demonstrate how elevated flows are transferred out of the primary channel and distributed along the interconnected secondary channel network, creating a diverse set of hydraulic environments. Areas between the channels rapidly become inundated as flows increase, dissipating flow energy. Shear stress estimates throughout the study site reveal a generally reduced ability to mobilise sediments and erode channel margins, in comparison to a single-thread reach immediately downstream. Anabranched secondary channels appear to operate in disequilibrium and act predominantly as aggradational zones, although with some evidence of scour at channel bifurcation and confluence points. It would appear that the topographic character of anabranching sites efficiently manages flood flow energy, activating secondary channels and low elevation areas to distribute flood flows. These findings contrast with the hydraulic data from an adjacent single-thread reach, characterised by flood flows concentrated in-channel creating a high erosive potential. We propose that 
anabranching rivers could play an important role in natural flood and sediment management in many UK river systems.

\section{Introduction}

Anabranching and anastomosing rivers represent a major group of rivers that exhibit a multi-thread channel network divided by stable islands often colonized by woody vegetation and associated with wetland areas. Despite anabranching being the prevailing river pattern found along alluvial tracts of the world's largest rivers, it is the least understood channel type (Jansen and Nanson, 2004). Major differences exist concerning their definition (see Carling et al., 2014 for a review), and the causes of their existence (Kleinhans et al., 2012). We follow the scheme of Nanson and Knighton (1996) who treat all non-braided multi-thread channels as 'anabranching', using the term to describe both low (sand-dominated) and high energy (gravel-bed) multi-thread systems in their six-fold channel classification. These workers identify two classes of gravel-dominated anabranched systems (Types 5 and 6); one of which is laterally active. The active (Type 5) channels are analogous to wandering channels (Desloges and Church, 1989), in that they often exhibit a less stable, dominant channel with multiple (more stable) anabranches, and may also alternate between multi- and single-thread reaches. These channels may be initiated by enhanced sediment supply, and log jams, and substantial lateral activity is often a feature. Nanson and Knighton (1993) also suggest that this type of anabranching may be driven by the needs to maintain bedload transport efficiency. Avulsion channels may form on the floodplain and fill with sediment to form large bars that become colonised with vegetation (Nanson and Knighton, 1996). Type 6 anabranching channels are more stable and form through log jams or sediment 
accumulation. The Wolsingham site is a high energy multi-thread gravel-bed river, with vegetated islands displaying the character of type 5 and type 6 anabranched channels to describe the study site used in this paper.

Anabranched river channels in the UK were arguably the dominant channel type before historic channel management practice led to their loss, with most lowland medieval rivers either inactively meandering or anabranching (Lewin, 2010). For example, Lewin (2010) presents cartographic evidence for anabranching morphology for tributaries of the lower Thames, specifically the Rivers Coln and Lea. Large and Petts (1996) also report historic anabranching for reaches for the River Trent in Nottinghamshire. Anabranching rivers are rare in the UK today and channel and floodplain management practices are inhibiting their development through vegetative succession suppression. However, there is evidence of a return to an anabranching channel form on a number of UK rivers, and this appears to be coincident with cessation of intensive floodplain management practice loci (Heritage et al., 2016).

No process-based studies on anabranching systems in the UK are available in the literature, possibly reflecting their rarity. On some UK rivers, localised anabranching systems can occur in locations where river-floodplain interaction has been allowed to occur unimpeded. They exhibit a stable multi-channel planform separated by well vegetated bars and islands, however they have developed on moderate to high energy gravel-dominated rivers (sensu Nanson and Knighton, 1996) unlike the lower energy anastomosing systems transporting cohesive sediments more commonly reported in the literature (Makaske, 2001). This paper investigates the energy regime of an anabranching reach of the River Wear, compared with an adjacent 
single-thread channel, contrasting the hydraulic forces acting to control the character of each system. A $2 \mathrm{D}$ hydraulic model is developed to simulate these changes across the flow regime.

\section{Methods}

\section{Study site characteristics}

The study focused on a $1.5 \mathrm{~km}$ reach of the upper river Wear at Wolsingham, County Durham, UK, situated at around $140 \mathrm{~m}$ AOD (Figure 1a). The $171.9 \mathrm{~km}^{2}$ catchment upstream drains a geology of impermeable Lower Carboniferous Limestone, overlain by peat in the headwaters and till and alluvium in the middle reaches. The relatively low permeability of these deposits and steep upper catchment results in a flashy hydrograph response The river has been impounded in its upper reaches by Burnhope reservoir, since 1937 but this does not attenuate flows. The river valley at Wolsingham is dominated by two late glacial and three Holocene terraces (Moore, 1994). The river bed at Wolsingham has a mean channel gradient of $0.007 \mathrm{~m} / \mathrm{m}$.

Figure 1

\section{Remote Sensing Information}

Interrogation of the $1 \mathrm{~m}$ resolution LiDAR DTM for the study reach, sourced from the UK EA Geomatics group, reveals a well-developed channel network, not at first visible from the DSM and aerial imagery (available for 1951, 1957, 1971, 2007, Wishart et al., 2008; Googlearth, 2016) of the reach due to dense riparian vegetation cover (Figure 1b,c). 


\section{Hydrological data}

Figure 2a shows the $62 \mathrm{~m}^{3} \mathrm{~s}^{-1}$ peak over threshold series for the river Wear recorded at Stanhope, sourced from the UK Environment Agency, situated $8 \mathrm{~km}$ upstream of the study site. These data are translated into an annual maximum return period curve (Figure 2b). The mean daily discharge recorded at Stanhope situated upstream of the study site is $3.92 \mathrm{~m}^{3} \mathrm{~s}^{-1}$ (Wishart et al., 2008). Daily flow statistics show that flows of $0.5 \mathrm{~m}^{3} \mathrm{~s}^{-1}$ are exceeded $95 \%$ of the time, and flows of $9.3 \mathrm{~m}^{3} \mathrm{~s}^{-1}$ are exceeded $10 \%$ of the time (Figure $2 \mathrm{~b}$ ). The 2 -yr return period discharge, approximately equivalent to the bankfull flow (Hey, 1975) for the channel in regime, is $124.5 \mathrm{~m}^{3} \mathrm{~s}^{-1}$. Data for peak flows (Figure 2a) indicate the most significant event in the historic flood series to be in 2005 (approaching $247 \mathrm{~m}^{3} \mathrm{~s}^{-1}$ ). However Wishart et al. (2008) indicate that a higher event of $297 \mathrm{~m}^{3} \mathrm{~s}^{-1}$ occurred in 1958.

Figure 2

\section{Fluvial Audit}

A fluvial audit (sensu Sear et al., 1995) was conducted along the study reach gathering observation-based evidence of current and former channel form and the influence of controlling processes. This revealed strong connectivity between the primary channel and adjacent riparian zone through the anabranched section, this connectivity reduced significantly through the single-thread reach downstream with the channel here displaying an inset character and a disconnected floodplain. The loose nature of the bed material suggests strong active transport along the river and 
flood flows had delivered some of this sediment through to secondary channels in the anabranched reach where they were forming functioning riffle and bar units. Fine sediment is also being transported through both channel types and was seen to accumulate in the bed and as marginal deposits, some of which were becoming consolidated. Many of the anabranching reach secondary channels only flow during elevated discharge and are otherwise characterised by residual isolated pools throughout most of the year. Large woody debris was common along the secondary channels forming stable features around which flow bifurcated. These features appear to exert some control on secondary channel development in the anabranched area. Woody debris was absent in the single-thread reach. Vegetation in the anabranched zone is characterised by mature ash, and sycamore woodland (Figure 3c) with smaller numbers of younger alder and willow closer to the main channel. An understory of shrub, bramble and ruderals are present across most of the site. This contrasts with a thin and disrupted woody riparian strip along the single thread section. Bank erosion was noted along both channel types, but was more prevalent through the single-thread reach.

Figure 3

\section{Historical channel changes}

Commercial gravel extraction took place at a number of locations on the Wear, including the site at Wolsingham, during the $20^{\text {th }}$ century involving intensive channel and floodplain management with periodic re-routing of flow allowing new areas of bed to be worked, and encouraging former pits to be refilled with sediment (Wishart et al., 2008). Cessation of gravel mining from the river at the site in the 1950s has 
allowed natural processes to operate with recovery towards a stable wooded anabranched system consisting of a dominant channel and multiple secondary channels. This unmanaged naturalisation of the watercourse developing a wellconnected floodplain area across the former widened mined reach is a key factor behind the historical channel recovery shown in Figure 4. The multiple secondary channels are not evident when viewing the 2007 aerial photograph due to dense woodland development, however they are visible on the LiDAR DTM (Figure 1b). Away from the mined reach progressive channel incision has disconnected the single thread channel from its floodplain.

Figure 4

There is a good historic record of morphodynamism for study reach that dates back to the early Tithe maps of 1839. Wishart et al. (2008) documents channel change for Wolsingham and a second site on the Wear at Harperley Park, using historic maps and aerial photographs for the period 1839-1991, and makes tentative links between channel changes and piecemeal gravel extraction. Aerial photographs for the site dating from 1951 are shown in Figure 4. The 1951 image clearly demonstrates the channel to be a dynamic multi-thread system, displaying a wandering channel morphology, with a combination of active mid-channel bars and some more stable vegetated islands. The 1957 image appears to show a less active channel; with some of the active bars become vegetated and more stable. The channel appears largely single-thread in nature, however the vegetation masks a stable multi-thread system beneath, that is only inundated during high flow events. The 1971 image (Figure 4) shows a more confined channel with some mid-channel bars. Some of the 
old abandoned channels are being farmed, and others have become well-vegetated. The channel is anabranching towards the downstream end of the reach, with wellvegetated islands. By 2007 there is a dominant channel, with occasional transverse bars, and the anabranched section is covered in dense vegetation. All of the old multi-channel network is now part of the wooded anabranched reach, activated at higher flows, further revealed on the LiDAR DTM (Figure 1b).

\section{Hydraulic modelling}

CAESAR-Lisflood (version 1.4) was used in reach mode to simulate depth-averaged hydraulics (Coulthard et al. 2013). The hydrodynamic flow model is based on the Lisflood FP code (Bates and De Roo, 2000), that conserves mass and partial momentum, and simulates in-channel hydraulic processes. Although Lisflood FP is primarily used as a flood inundation model it has also been used to examine channel morphodynamics (Wong et al., 2015). The LISFLOOD-FP component of CAESARLisflood is a one-dimensional inertial model derived from the full shallow water equations that is applied in the $\mathrm{x}$ and $\mathrm{y}$ directions to simulate two dimensional flow over a raster grid (Coulthard et al., 2013). As such CAESAR-Lisflood simulations must be regarded as only a first approximation to the problem, however Bates et al. (2010) and Neal et al. (2011) demonstrated that the model was capable of simulating flow depths and velocities within $10 \%$ of a range of industry full shallow water codes. Their simulations of gradually varying flows, revealed that velocity predictions were 'surprisingly similar' between the models and they suggest that Lisflood-FP model may be appropriate for velocity simulation across a range of gradually varied subcritical flow conditions. 
Bare-earth LiDAR, sourced from the EA Geomatics group was used to produce a 1m DEM for the study reach (Figure 1b). Surface grain size for the study reach measured using grid-by number sampling (Wolman, 1954), revealed a reach $D_{50}$ of $65 \mathrm{~mm}, D_{84}$ of $107 \mathrm{~mm}$, and $D_{99}$ of $175 \mathrm{~mm}$; generally coarser than the bulk sample grain size reported by Wishart et al. (2008). A general Mannings ' $n$ ' grain scale roughness value of 0.03 was calculated using the Strickler equation $\left(n=D^{1 / 6} / 21\right)$, where $D$ is the $D_{50}$ surface grain size, and this was used in the simulations. Additional form roughness variation in the form of morphology and planform variation is implicitly represented by topographic variation in the DEM. Given the small grid cell size a Courant Number of 0.3 was chosen to avoid computational model stability issues. The calculated Froude Number was limited to the default value of 0.8 and horizontal water flux threshold was also left as the default value of $0.00001 \mathrm{~m}$. The flow model was then run for a range of hydrographs ranging from $16 \mathrm{~m}^{3} \mathrm{~s}^{-1}$, equivalent to the daily flow exceeded $5 \%$ of the time (Figure $2 \mathrm{~b}$ ) and $198 \mathrm{~m}^{3} \mathrm{~s}^{-1}$, approximately equivalent to the $40 \mathrm{yr}$ return period. This flow remained in-bank along the inset single-thread sections of channel, however fully inundates the anabranched section.

The model was validated against dGPS, water surface height measurements taken at two different low flow gauged discharges $\left(5.2 \mathrm{~m}^{3} \mathrm{~s}^{-1}\right.$ and $7.8 \mathrm{~m}^{3} \mathrm{~s}^{-1}$ at three locations along the study reach. These elevation measurements were compared with simulated water surface elevations at the measurement points at equivalent discharges. Elevation differences were found to be $\pm 0.01 \mathrm{~m}$ of the measured values (Table 1). For these flows, the data suggest that the modelling provides a good 
estimate of channel hydraulics, based upon the water surface representing the hydraulic integrity of the reach. No high flow hydraulic measurements were taken at the site, however, a peak flood strandline estimate for the river (5/12/2012) was obtained from internet imagery (Glenister, 2015), at Causeway Road Bridge located in between the anabranched and single thread reaches (Figure 5). This strand equated to a peak flow discharge of $159.45 \mathrm{~m}^{3} \mathrm{~s}^{-1}$ measured at Stanhope Weir gauge station.

Table 1

Figure 5

The strand line is composed of fragments of woody vegetation that have collected in the low energy lee zone after the bridge abutment and was locally well defined following the contour line of the tarmac path next to the river. The elevation of the debris was found to be 136.4 masl from EA LiDAR of the reach (Figure 5). A stage discharge relationship was developed for the open water area close to the bridge from the multiple water surface simulations output from CAESAR Lisflood (Figure 5) and a discharge of $163.44 \mathrm{~m}^{3} \mathrm{~s}^{-1}$ obtained for the strandline elevation. This is a $2.5 \%$ overestimation compared to the gauge.

Depth average velocity output from each simulation was then used to estimate point shear stress $\left(\tau_{o}\right)$ using Wilcock's (1996) equation

$$
\frac{U}{u_{*}}=\frac{1}{\kappa} \ln \left(\frac{h}{\ell z_{0}}\right)
$$


where the shear velocity $u_{*}=\left(\tau_{o} / \rho\right)^{1 / 2}, \rho$ is water density, $U$ is depth average velocity, $\kappa$ is von Karmens constant (taken to be 0.4 ), $\ell$ is the base of the natural logarithms, $h$ is local water depth, $z_{0}$ is an estimate of bed roughness. Under appropriate flow conditions an estimate of $u_{*}$ termed $u_{* h}$ may be derived using (1), using simulated values of $U$ and $h$. When both grain and form roughness exist, $u_{*_{h}}$ is the total drag composed of both form drag and skin friction (Wilcock, 1996). Using this approach, Wilcock (1996) found that local bed shear stress was estimated to within $3 \%$ of that measured where relatively simple flow geometries were involved.

Predictions of depth and shear stress were computed at a $1 \mathrm{~m}^{2}$ resolution across the channel and then were visualised in SURFER (Figure 6) Comparisons were made between the anabranching upstream reach and the downstream single-thread reach. Unit shear stress (shear stress per unit area) and total shear stress (summation of shear stress values for channel segments) were calculated using the $1 \mathrm{~m}^{2} 2 \mathrm{D}$ hydraulic model outputs for each of these sub-reaches for the full range of simulations, in order that comparisons in energy between the two channel styles could be made.

Figure 6

\section{Results}

Flow depth and shear stress patterns 
Figure 6a shows flow depth and areal inundation extent throughout the study reach over the flow regime, demonstrating how the abandoned multi-thread channel areas of the anabranching reach gradually become inundated with increasing flood peaks. Progressive inundation characteristics for the anabranched and single-thread subreaches are shown for the range of simulated flows in Figure 6, and clearly illustrate the contrasting response to flood flows between the two channel types. The anabranched reach doubles its flow area at $68 \mathrm{~m}^{3} \mathrm{~s}^{-1}$, as one of the secondary channels becomes inundated, whilst the flow area within the single-thread reach remains approximately constant (Figure 6a). Downstream of the anabranching reach, confinement of flow to single-thread morphology results in significantly greater flow depths compared with the anabranched reach, for a comparative discharge (Figure 6a). Flow concentration and resultant greater flow depths in the singlethread reach increase the probability of sediment transport, and erosion of the bed and banks. These findings suggest that the single-thread reach is strongly inset within the floodplain, and is no longer functionally connected to its floodplain. However the anabranched section behaves differently; with a primary channel at low flow and an ephemeral multithread secondary channel network and wooded zone, that acts as a new floodplain level during high flows.

The spatial distribution of shear stress throughout the study reach shown in Figure $6 \mathrm{~b}$, demonstrates how energy appears to be dissipated through the anabranched channels as flood stage rises. The highest shear stress peaks have a tendency to be located in the single-thread reach. In the anabranched section, shear stresses tend to be low at channel heads and higher at downstream channel confluences. This can be seen on a local scale for the $198 \mathrm{~m}^{3} \mathrm{~s}^{-1}$ simulation (Figure 6c). Differences in 
shear stress between anabranched and single-thread sections are revealed graphically through a plot of simulated shear stress for the high flow $\left(198 \mathrm{~m}^{3} \mathrm{~s}^{-1}\right)$ plotted against distance downstream along the channel thalweg in Figure 7. Typical shear stress values are below $80 \mathrm{Nm}^{-2}$ in the anabranched section, compared with a much more variable pattern shown for the single-thread section; with peaks in excess of $200 \mathrm{Nm}^{-2}$. Kurtosis and skewness statistics based upon the distribution of shear stress values over the range of simulated flows further highlight differences between the single-thread and anabranching reaches (Figure 8). Although both reaches show a decline in both Kurtosis and skewness as flow increases, the singlethread reach consistently demonstrates greater kurtosis and skewness, suggesting that shear stress values are concentrated into a narrower range, and are skewed towards higher shear stress values compared with the anabranched reach. This suggests that the single-thread reach should have greater sediment transport potential and potential to scour it's bed and banks. The flattening out of the curves for the anabranched reach in Figure $8 a$ and $b$, suggests a wider range (less skewed) of shear stresses are exerted on the bed and banks, and less peaked distribution, at flows in excess of around $60 \mathrm{~m}^{3} \mathrm{~s}^{-1}$. This could reflect the effects of bar submergence.

Figure 7

Figure 8

\section{Sediment transport potential}

The geomorphic effectiveness of the shear stress patterns may be assessed through comparing the simulated shear stress relative to the critical shear stresses $\left(\tau_{c}\right)$ for 
bedload movement, calculated from the reach-scale surface grain-size characteristics

$$
\tau_{c}=\theta\left(\rho_{s}-\rho\right) g D_{50}
$$

where $\theta$ is the critical dimensionless shear stress $(0.047), \rho_{s}$ is the sediment density, $\rho$ is the fluid density, $g$ is acceleration due to gravity, and $D_{50}$ is the median surface grain-size. Typically shear stresses did not exceed $100 \mathrm{~N} \mathrm{~m}^{-2}$ in the anabranching sub-reach, and suggest partial mobilisation of material up to the $D_{50}$, however was insufficient to mobilise grain sizes of the $D_{50}$ and above (Figure 7). Low shear stresses are indicative of a generally stable bed during flood conditions for the anabranched sub-reach, and a trend towards aggradation. However, where the flow is confined into a single-thread channel downstream, shear stresses are significantly greater, peaking at close on $250 \mathrm{Nm}^{-2}$. This shear stress is sufficient to mobilise bed material around the $D_{84}$ percentile in a number of locations along this reach, suggesting a near fully mobile bed and a much greater potential for morphological change. This also helps to explain the incised nature of the single-thread reach, apparent from the LiDAR DEM. Evidence of bank erosion is also evident at a number of locations along the single-thread section, possibly in response to incision.

Total shear stress for both single-thread and anabranching channel styles are plotted against discharge in Fig 9a, revealing that the anabranching reach is indicative of consistently greater energy over the flow regime compared with the single-thread reach downstream. However the anabranched reach has a much greater flow area in comparison to the single-thread reach. When shear stress is scaled by unit area, a 
very different picture is evident, with flow energy consistently lower in the anabranched reach (Figure 9b). Lower unit shear stress data demonstrates that energy is dissipated more effectively in the anabranched reach. At higher discharges flow is diverted into the anabranching channel network, flowing over a greater surface area compared with a single-thread channel, with increased overall roughness, including the influence of vegetation roughness; further resulting in energy loss. The initial rate of increase in unit shear stress up until $36 \mathrm{~m}^{3} \mathrm{~s}^{-1}$ is greater for both anabrancing and single-thread sections, possibly reflecting flow contained within the dominant channel throughout the study reach. At flows beyond $36 \mathrm{~m}^{3} \mathrm{~s}^{-1}$, the anabranched section starts to becoming inundated, and this influences the rate of unit shear stress increase both within the anabranched and single thread section downstream. In general the rate of unit shear stress increase with discharge is greater for the single-thread section, reflecting the effects of the smaller channel cross-section area.

Figure 9

\section{Potential for morphological change}

Potential scour maps, indicating the areas that exceed the critical shear stress to mobilise the $D_{50}$, are shown for each flow simulation in Figure 10. Potential for scour of the surface bed sediments is almost exclusively confined to the single-thread section of channels, and parts of the primary channel that runs through the anabranched section. As discharge rises, the shear stress capable of mobilising the bed surface gradually increases. Areas of potential bed mobilization are very patchy for the lower discharge simulations, however progressively greater areas of the bed 
are susceptible for mobilization with increasing flow. The majority of the secondary channels in the anabranched section consistently appear unable to transport bed surface sediments, however for flows in excess of $96 \mathrm{~m}^{3} \mathrm{~s}^{-1}$, the tail end of the secondary channel system, just before it rejoins the primary channel, does appear to show potential for bed scour. The spatial patterns shown, suggest that bed material fed in to the secondary channels from upstream, is likely to stall in the channel network, whilst the downstream end may see some headward progressing incision. In effect the secondary channels are in disequilibrium with the rest of the system, and both these mechanisms provide potential pathways for avulsion. The primary channel running through the anabranched section, generally appears efficient at mobilizing bed surface sediments.

Figure 10

\section{Discussion}

Research focused on the hydraulic characteristics of anabranching channels are limited (e.g. Harwood and Brown, 1993; Jansen and Nanson, 2004; Makaske et al., 2009), with the majority of studies focussing upon the morphodynamics of these systems (e.g. Knighton and Nanson, 1996; Makaske, 2001; Burge, 2006; Huang and Nanson, 2007; Kleinhans et al., 2012). This paper has compared the hydraulic characteristics of anabranching and single-thread morphology. A clear contrast in hydraulic behaviour was simulated across the flow regime, with the single-thread reach displaying consistently higher shear stresses. The anabranching reach had a primary channel with lower shear stresses compared to the single-thread reach 
downstream, and a secondary system of anabranches that start being inundated at flows in excess of $36 \mathrm{~m}^{3} \mathrm{~s}^{-1}$ (Return Period 0.4 years). These were characterised initially by very low shear stresses, before exhibiting higher values at anabranch confluences in the higher flow simulations, analogous to Harwood and Brown's (1993) findings on the Gearagh, wooded anabranched system on the River Lee, Ireland.

Our findings also indicate strongly contrasting channel-floodplain connectivity between the two adjacent reaches. Interrogation of historical photographs and maps suggests that the single-thread section was previously active, with mobile gravel bars. Gravel mining is likely to have resulted in sediment starvation to the singlethread reach downstream, and promoted incision. Since the 1970s these have been vegetated and stabilised, with much less evidence of lateral instability, further reducing sediment supply. It is likely that the single-thread reach has incised as a result of shear stresses capable of mobilising the surface bed material, and the channel has become disconnected from its former floodplain: flow remained within the channel even at the highest simulation $\left(198 \mathrm{~m}^{3} \mathrm{~s}^{-1}\right)$. The anabranching reach begins to inundate floodplain sub-channels at around $35 \mathrm{~m}^{3} \mathrm{~s}^{-1}$; a value well below the traditional bankfull return period occurring on 5 days/yr on average (Hey, 1975). Anabranching channels typically flood overbank more frequently than single-thread channels, resulting in greater sediment delivery to floodplains and island-ridges flanking the anabranches (Jansen and Nanson, 2004).

Unit shear stress results for the study site also suggest a marked contrast, with the anabranching reach rapidly dissipating energy across the multithread sub-channel 
network during elevated flows. Jansen and Nanson (2004) report similar observations for Magela Creek, and suggest that anabranching morphology is more efficient at using excess energy at high stage, through dissipating the energy over the multiple channel network, where it is met with higher roughness in comparison with single-thread channels. Interestingly Jansen and Nanson (2004) suggest stream power between the two channel sub-reaches diverge at discharges above bankfull. At the Wolsingham site, shear stresses diverge at discharges well below bankfull. Essentially the shear stresses are always greater in the single-thread section, as flow depth is greater and channel width narrower, in comparison to the anabranched section. For a given increase in discharge, the rate of increase in shear stress is consistently greater in the single-thread section, as channel width does not change as significantly as it does in the anabranched section, and flow depths increase at a faster rate in the single-thread section due to flow confinement.

Shear stresses in the anabranched section do not appear competent enough to mobilise the surface $D_{50}$ at peak flows throughout the network of secondary channels. However evidence from the fluvial audit (Figure 3a) indicates that some bedload is fed into, and deposited in some of the secondary channels suggesting a degree of transport and potential slow aggradation. Huang and Nanson (2007) have shown that increasing the number of channels without adjusting channel slope can lead to a proportional decrease in flow efficiency, and hence sediment transport capacity. It is likely that the secondary channels in the anabranching section at Wolsingham are aggradational, and hence in disequlibrium (sensu Makaske et al., 2009). Aggradational disequilibrium anabranched systems may transport and stored 
sediment through a continual process of channel creation and old channel abandonment (Huang and Nanson, 2007)

It would appear that the anabranched reach at Wolsingham has developed following the cessation of intensive channel management (gravel extraction, grazing and wood management), allowing barforms to stabilise through vegetative succession. A diverse mosaic of vegetation can potentially develop, an observation shown for wandering channel morphology on the river Feshie by Gilvear and Willby (2006). The diversity in hydraulic conditions modelled for the Wolsingham site have the potential to support an unusually varied biota and range of environmental processes (Naiman and Dechamps, 1997).

The overall evidence from our 2D hydraulic modelling suggests a hydraulic regime broadly commensurate with sediment transport processes, however more extreme flows display a hydraulic diversity which promotes morphological change, enhanced by the local hydraulic effects of the vegetation, for example dead wood (Gurnell, 2014). It is clear that bedload can be fed in to the anabranches at high flow, which could induce avulsion, through channel blockage, erosion and activation of new channels through existing islands or floodplain.

Locally anabranching sections on rivers appear to be important for regulating energy along the river long-profile. Although our work suggests local disequilibrium within the anabranched section itself, when the full reach is considered, including the single-thread section, the anabranched section could be important for maintaining channel stability. Referring to the Columbia River, Huang and Nanson (2007) 
suggest that anabranching may be the most efficient means of accomplishing sediment sequestration across an aggrading floodplain. Without anabranching, bedload forced through a single-thread channel may lead to a much less stable condition. In a single-thread channel a significant reduction in channel width results in flow confinement and increased shear, that could induce bank instability. Hence retention and management of locally anabranching sites on UK rivers, could be important for maintain quasi-equilibrium, when considering longer reaches. In addition, their increased storage capacity, when compared with single-thread sections, means that locally anabranching sections of river channel have the potential to provide an important natural flood management tool.

\section{Conclusions}

The topographic character of anabranching channels efficiently manages flood flow energy, activating secondary channels and low elevation areas to distribute flood flows; creating a dynamically stable river environment. These findings contrast with the hydraulic data from an adjacent single-thread sub-reach, characterised by concentrated flood flows and a high erosive potential. In particular, anabranching channels

- $\quad$ flood overbank more frequently than single-thread channels

- $\quad$ are less energetic than single-thread channels and the channel form, are aggradational and in disequilibrium

- $\quad$ have a significantly more diverse hydraulic diversity in comparison to singe-thread channels 
- $\quad$ are the most common channel type on the worlds largest rivers, and there appears to be evidence that anabranching reaches are developing at a number of UK sites where intensive floodplain management has been abandoned.

The site at Wolsingham suggests that anabranching reaches will develop naturally where lateral connectivity is strong and floodplain utilisation is low allowing vegetation succession to progress. This channel type has potential therefore for increasing biodiversity of UK watercourses, inducing the provision of rare or endangered habitat. An associated riparian fauna, including wading birds, fish and amphibians will also thrive in this habitat. Therefore, allowing vegetation development would not only have a beneficial effect for flood management purposes, but would also enhance riparian habitat.

\section{References}

Bates P, De Roo P. 2000. A simple raster-based model for flood inundation simulation. Journal of Hydrology 236: 54-77.

Bates, P, Horritt, Ms, \& Fretwell, J. 2010. A simple inertial formulation of the shallow water equations for efficient two-dimensional flood inundation modelling, Journal of Hydrology, 387 (1-2), 33-45

Burge, L. 2006. Stability, morphology and surface grain size patterns of channel bifurcation in gravel-cobble bedded anabranching rivers. Earth Surface Processes and Landforms, 31, 1211-1226. 
Carling P, Jansen J, Meshkova L. 2014.Multichannel rivers: their definition and classification. Earth Surface Processes and Landforms 39: 26-37.

Coulthard TJ, Neal JC, Bates PD, Ramirez J, Almeida GAM, Hancock GR. 2013. Integrating the LISFLOOD-FP 2D hydrodynamic model with the CAESAR model: implications for modelling landscape evolution. Earth Surface Processes and Landforms 38: 1897-1906

Gilvear D, Willby N. 2006. Channel dynamics and geomorphic variability as controls on gravel bar vegetation; River Tummel, Scotland. River Research and Applications 22: $457-474$.

Gregory SV, Boyer KL, Gurnell A (Eds.). 2003. The ecology and management of wood in world rivers. American Fisheries Society, Symposium 37, Bethesda, Maryland.

Gurnell A. 2014. Plants as river system engineers. Earth Surface Processes and Landforms 39: 4-25.

Harwood K, Brown AG. 1993. Fluvial processes in a forested anabranching river:flood partitioning and changing flow patterns. Earth Surface Processes and Landforms 18: 741-748.

Heritage GL, Entwistle N, Milan D. 2016. Alluvial Anastomosed Channels: The preferred channel type on active UK rivers. Proceedings of the $11^{\text {th }}$ ISE Symposium, Melbourne, Australia.

Hey RD. 1975. Design discharge for natural channels. In: RD Hey, TD Davies (eds.) Science, Technology and Environmental Management, Saxon House, 73-88. Jansen JD, Nanson GC. 2004. Anabranching and maximum flow efficiency in Magela Creek, northern Australia. Water Resources Research 40: W04503, doi:10.1029/2003WR002408. 
Huang, HQ, Nanson, GC. 2007. Why some rivers develop an anabranching pattern. Water Resources Research, 43, W07441.

Kleinhans MG, de Haas T, Lavooi E, Makaske, B. 2012. Evauating competing hypotheses for the origin and dynamics of river anastomosis. Earth Surface Processes and Landforms 37: 1337-1351.

Knighton AD, Nanson GC. 1993. Anastomosis and the continuum of channel pattern. Earth Surface Processes and Landforms 18: 613-625.

Large ARG, Petts GE. 1996. Historical channel-floodplain dynamics along the River Trent: implications for rehabilitation. Applied Geography 16: 191-209.

Lewin J. 2010. Medieval environmental impacts and feedbacks: the lowland floodplains of England and Wales. Geoarchaeology: An International Journal 25: 267-311.

Makaske B. 2001. Anabranching rivers: a review of their classification, origin and sedimentary products. Earth Science Reviews 53: 149-196.

Moore EN. 1994. Glacial Geology and Geomorphology of Weardale. Unpublished PhD Thesis, University of Durham, UK.

Naiman RJ, Décamps H. 1997. The ecology of interfaces-riparian zones. Annual Review of Ecology and Systematics 28: 621-658.

Nanson GC, Knighton AD. 1996. Anabranching rivers: their cause, character and classification. Earth Surface Processes and Landforms 21: 217-239.

Neal, J., Villanueva, I., Wright, N., Willis, T., Fewtrell, T. and Bates, P. (2012), How much physical complexity is needed to model flood inundation?. Hydrol. Process., 26: 2264-2282.

Sear DA, Newson MD, Brooks A. 1995. Sediment related river maintenance: the role of fluvial geomorphology. Earth Surface Processes and Landforms 20, 629-647. 
Wilcock, P.R. 1996. Estimating local bed shear stress from velocity observations, Water Resources Research, 32(11), 3361-3366.

Glenister D. 2015. Storm Desmond - River Wear Wolsingham 2015. Available at: https://www.youtube.com/watch?v=bZgH5PvaO-g [Accessed 27 March 2018].

Wishart D, Warburton J, Bracken L. 2008. Gravel extraction and planform change in a wandering gravel-bed river: the Wear, Northern England. Geomorphology 94: 131-152.

Wong JS, Freer JE, Bates PD, Sear DA, Step E. 2015. Sensitivity of a hydraulic model to channel erosion uncertainty during extreme flooding. Hydrological Processes 29: 261-279.

Wolman MG. 1954. A method of sampling coarse river gravels. Trans., Am. Geophys. Union 35: 951-956. 


\section{List of Figures}

Figure 1 River Wear catchment, and study reach at Wolsingham a) Catchment map, b) LiDAR image of study reach. The location of the high flow validation measurement (reported in Figure 5) is indicated by the red star and is positioned immediately downstream of the Causeway Road Bridge in Wolsingham.

Figure 2 Flow data for the River Wear at Stanhope, a) Annual Flood peak series, b) Flow frequency curve.

Figure 3 Anabranching study reach; a) Low flow channel with fresh gravel, indicative of high energy transport at higher flows, b) variety of vegetation, c) inundation of ephemeral anabranches during a flood event, d) low energy distributary with fine sediment deposition.

Figure 4 Aerial photographs for the study reach highlighting a transition from wandering, through to stabilizing anabranching to fully anabranched river type, highlighted in red on the 2007 image (Googleearth.co.uk).

Figure 5 a) Location of high flow validation immediately downstream of the Causeway Road Bridge in Wolsingham, with high flow strand-line debris visible in the bottom right corner of the image (Glenister, 2015). b) Stage-discharge curve is plotted for this site using results from our simulations. Water level data for the 5th December 2015 returned a discharge of $159.45 \mathrm{~m}^{3} \mathrm{~s}^{-1}$; within $2.5 \%$ of the actual recorded at Stanhope Weir gauging station. 
Figure 6 Results CAESAR-Lisflood model runs, demonstrating a) flow depth and inundation of the anabranched channel network with increasing discharge, b) Spatial patterns of shear stress through the reach, c) close-up of shear stress patterns for $198 \mathrm{~m}^{3} \mathrm{~s}^{-1}$ simulation.

Figure 7 Downstream variations in average shear stress for the $198 \mathrm{~m}^{3} \mathrm{~s}^{-1}$ simulation, demonstrating significantly lower shear stress peaks, and less variability in shear stress in the anabranching reach, compared with single-thread downstream. Grey line is the running mean.

Figure 8 Summary statistics for shear stress over the flow regime for the singlethread and anabranching subreaches, a) Kurtosis, b) Skewness.

Figure 9 a) Total shear stress for adjacent anabranching and single-thread reaches, b) Unit shear stress over the flow regime for study reaches.

Figure 10 Spatial patterns of scour potential through the study reach based upon the critical shear stress for entrainment of the bed surface $D_{50}$.

\section{List of Tables}

Table 1. Comparison of measured and simulated water elevations for the study reach $(m)$ 
Table 1. Comparison of measured and simulated water elevations for the study reach $(m)$.

\begin{tabular}{|l|l|l|l|l|}
\hline & & Upstream & Mid & Downstream \\
\hline \multirow{3}{*}{$\mathrm{Q}=5.2 \mathrm{~m}^{3} \mathrm{~s}^{-1}$} & Measured & 140.04 & 138.12 & 133.86 \\
\cline { 2 - 5 } & Modelled & 140.029 & 138.107 & 133.889 \\
\cline { 2 - 5 } & Error & -0.011 & -0.013 & 0.029 \\
\cline { 2 - 5 } & & & & \\
\hline $\mathrm{Q}=7.8 \mathrm{~m}^{3} \mathrm{~s}^{-1}$ & Measured & 138.58 & 138.11 & 133.25 \\
\cline { 2 - 5 } $05 / 08 / 2012$ & Modelled & 138.581 & 138.093 & 133.248 \\
\cline { 2 - 5 } & Error & 0.001 & -0.017 & -0.002 \\
\hline
\end{tabular}


a)

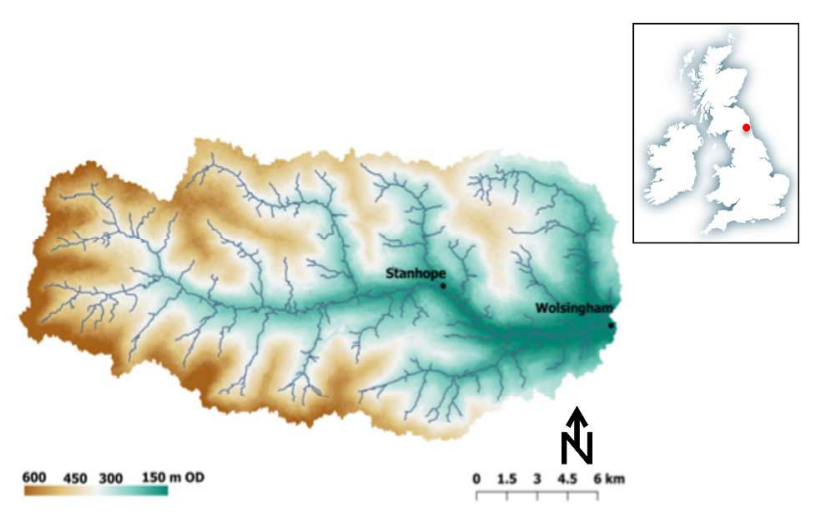

b)

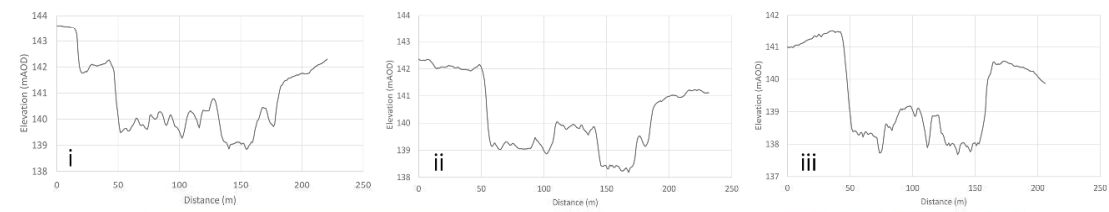

$629 \times 891 \mathrm{~mm}(200 \times 200 \mathrm{DPI})$ 
a)

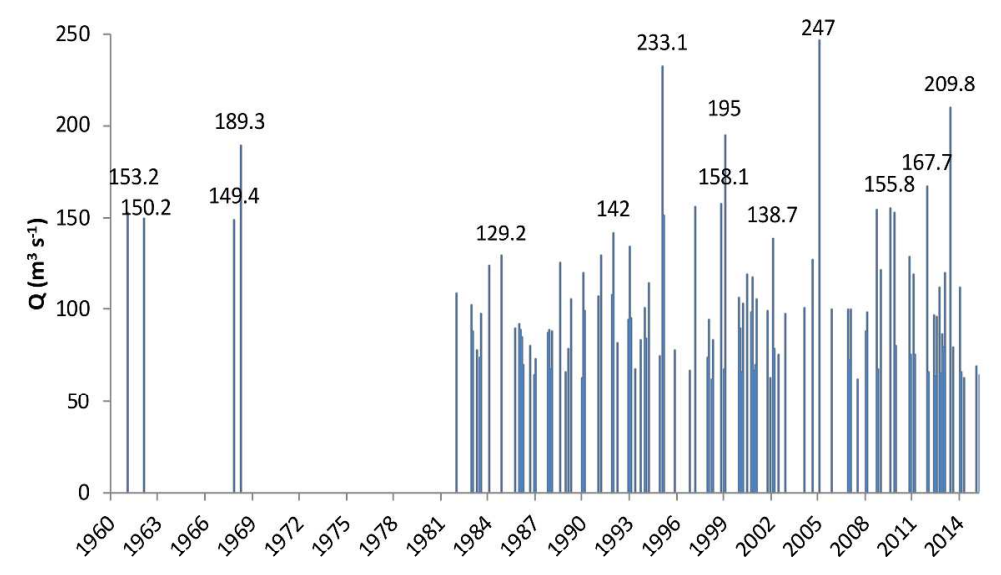

b)

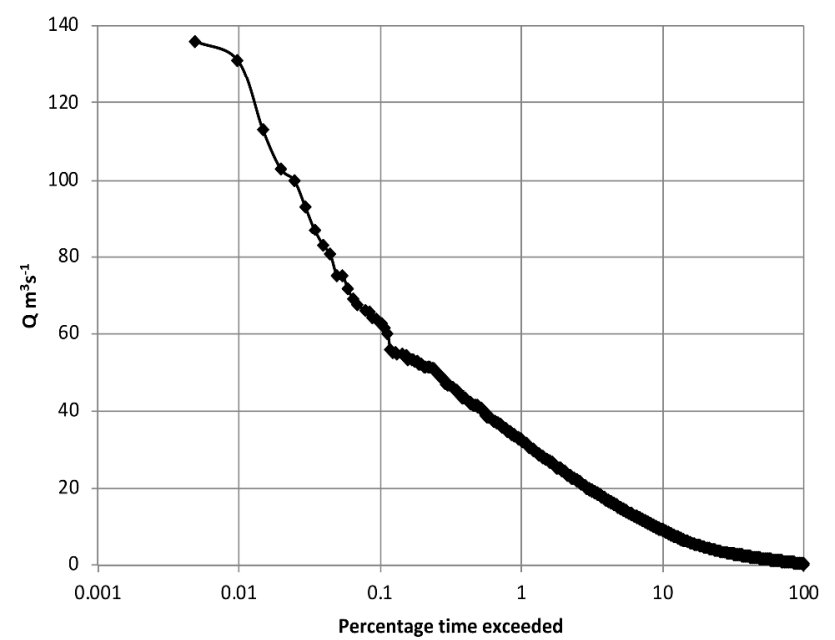

F2

Figure 2.

$629 \times 891 \mathrm{~mm}(200 \times 200$ DPI $)$

http://mc.manuscriptcentral.com/rra 


\section{Unable to Convert Image \\ The dimensions of this image (in pixels) are too large to be converted. For this image to convert, the total number of pixels (height $x$ width) must be less than 40,000,000 (40 megapixels).}




\section{Unable to Convert Image \\ The dimensions of this image (in pixels) are too large to be converted. For this image to convert, the total number of pixels (height $x$ width) must be less than 40,000,000 (40 megapixels).}




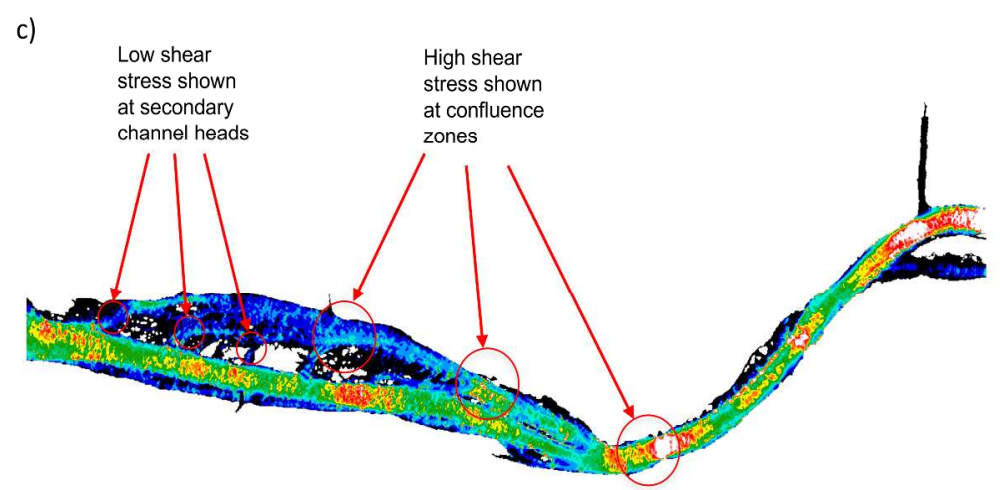




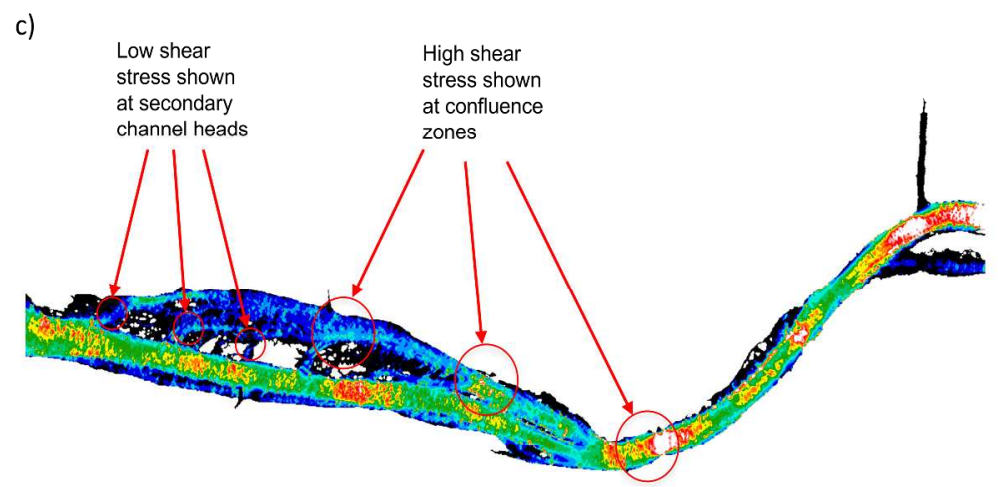




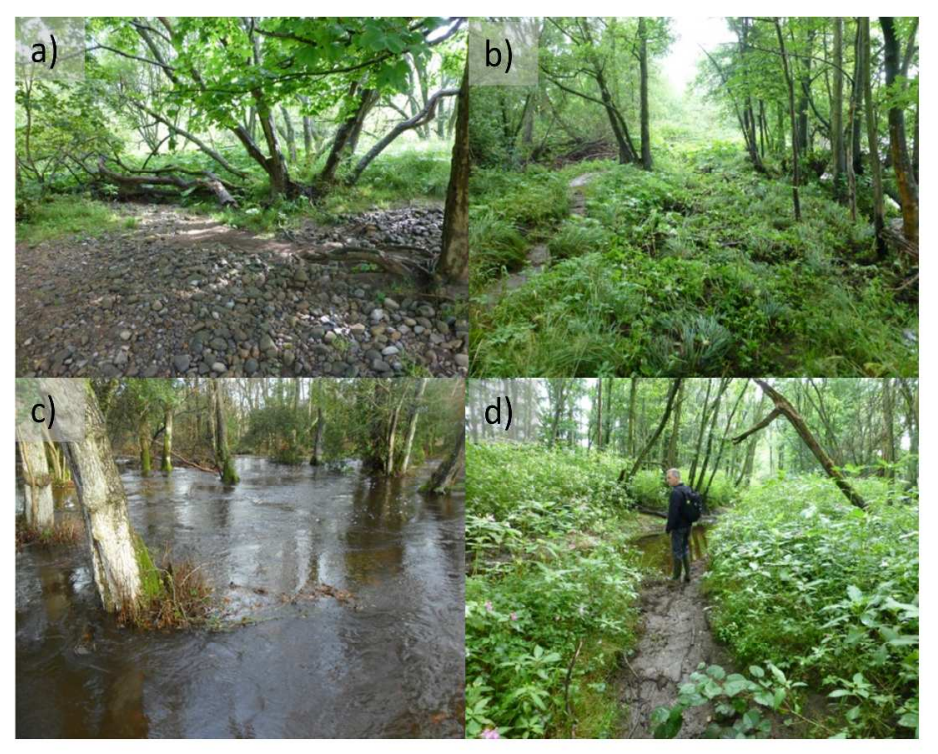

F3

Figure 3.

$629 \times 891 \mathrm{~mm}(200 \times 200$ DPI $)$ 

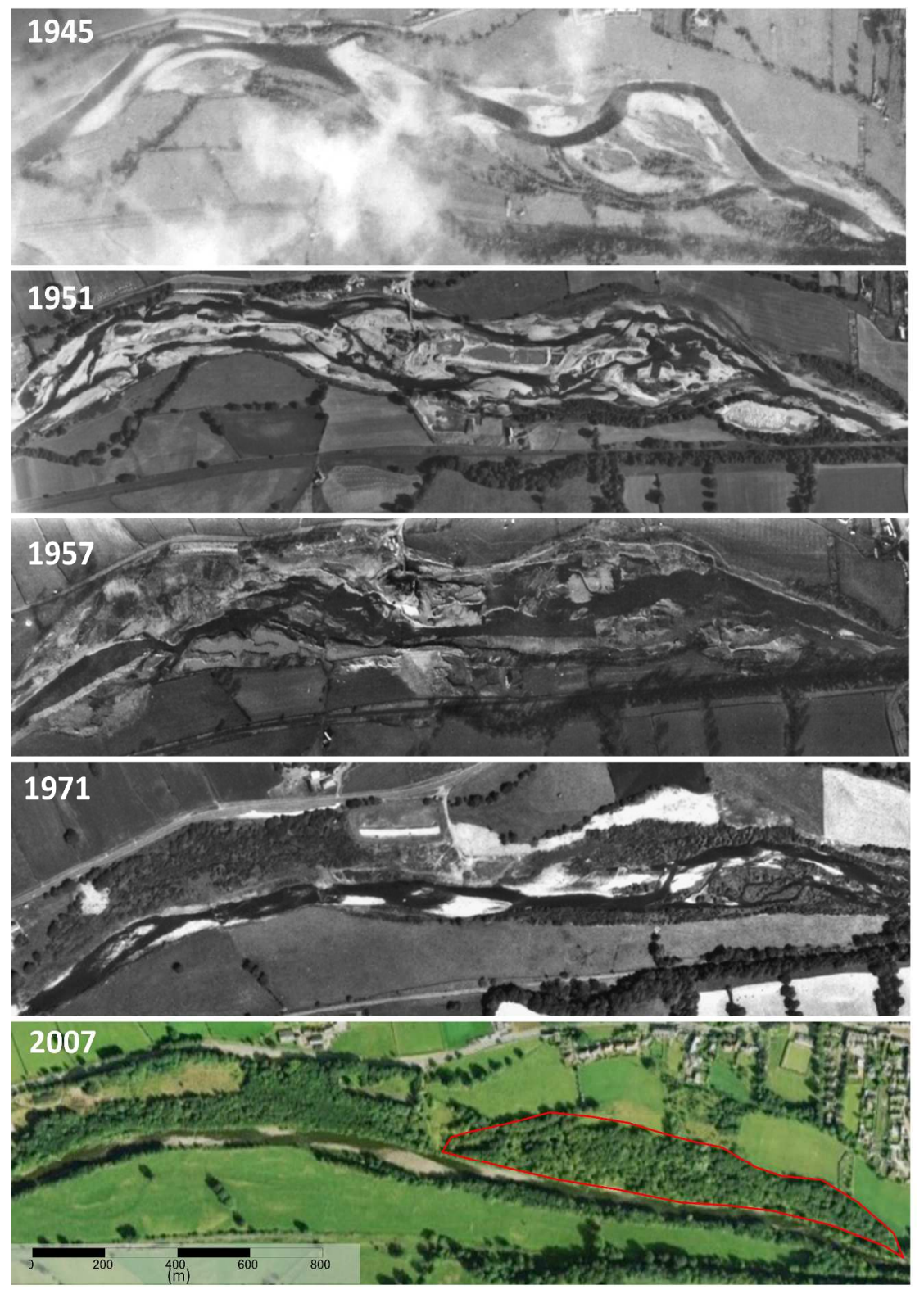

Figure 4.

$629 \times 891 \mathrm{~mm}(200 \times 200 \mathrm{DPI})$ 


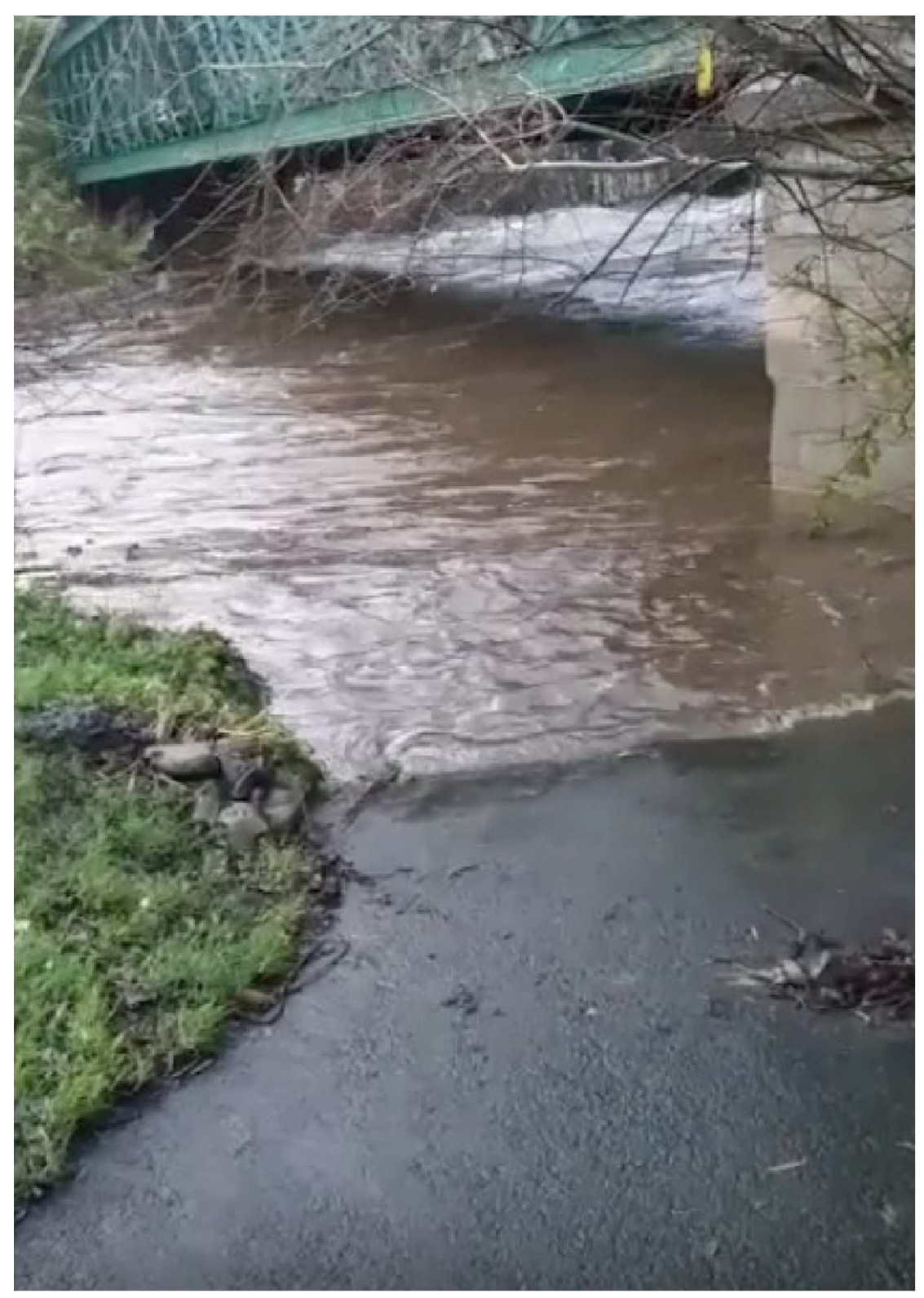

Figure 5A.

$629 \times 891 \mathrm{~mm}(200 \times 200$ DPI $)$ 


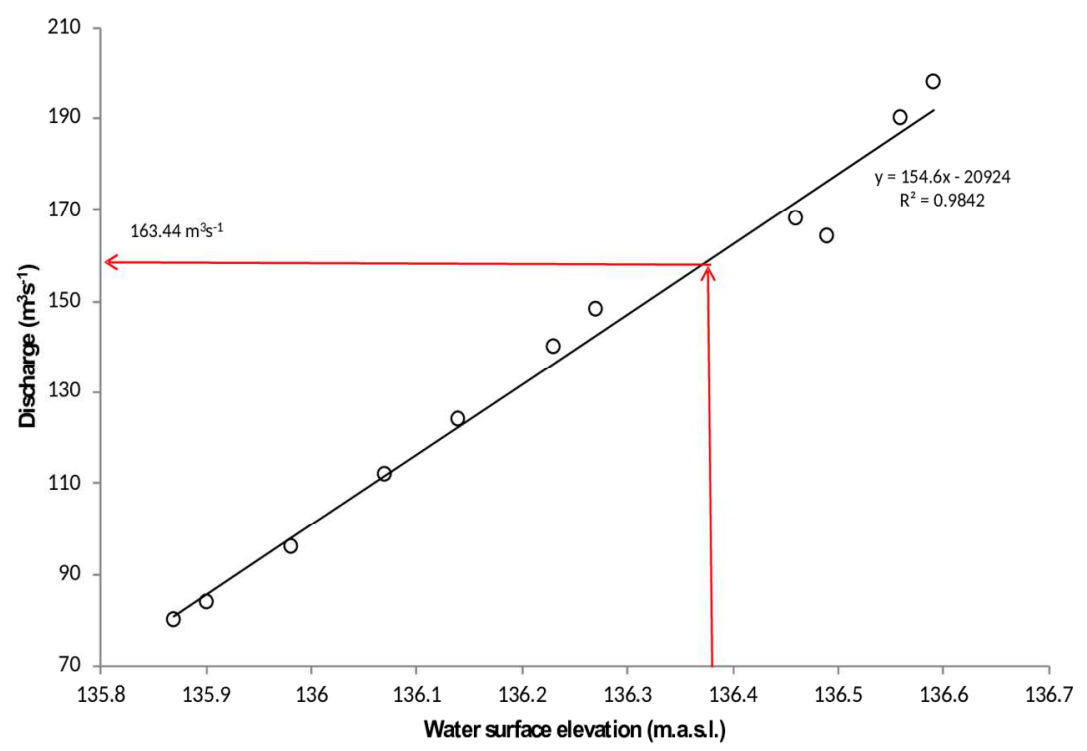

Figure 5B.

$629 \times 891 \mathrm{~mm}(200 \times 200$ DPI $)$

http://mc.manuscriptcentral.com/rra 


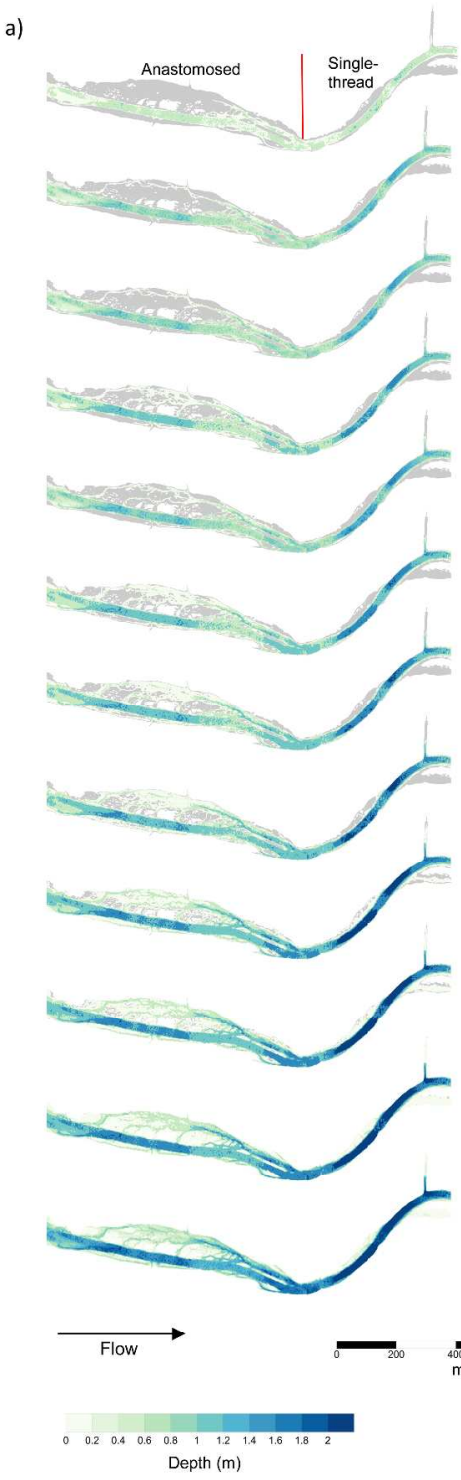

b)
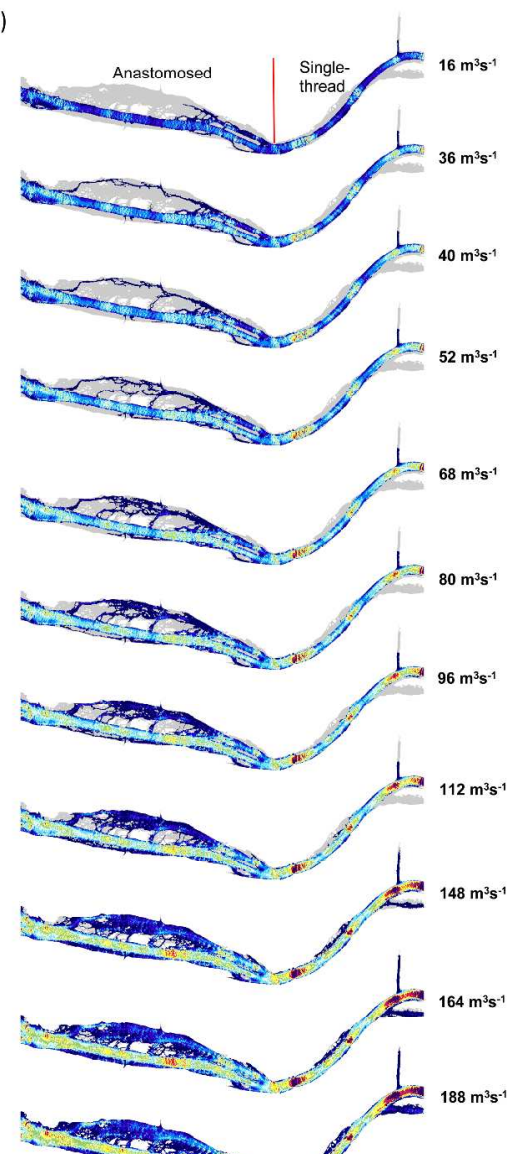


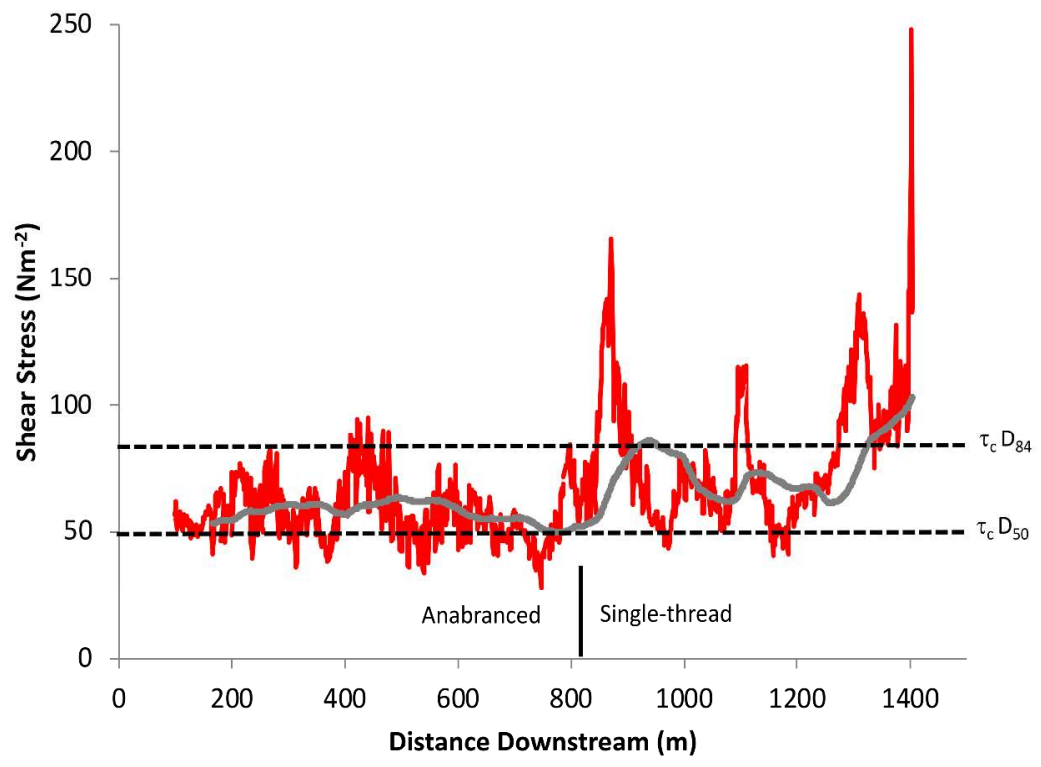

Figure 7.

$629 \times 891 \mathrm{~mm}(200 \times 200$ DPI $)$ 
a)

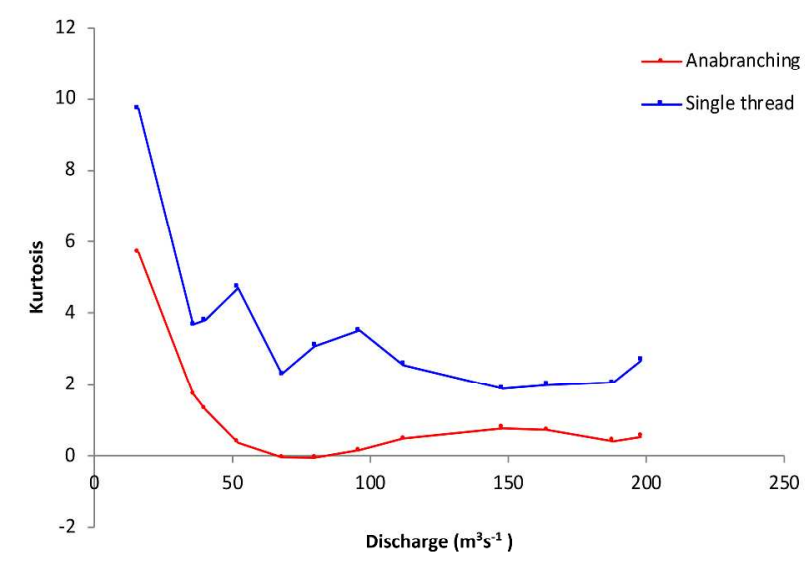

b)

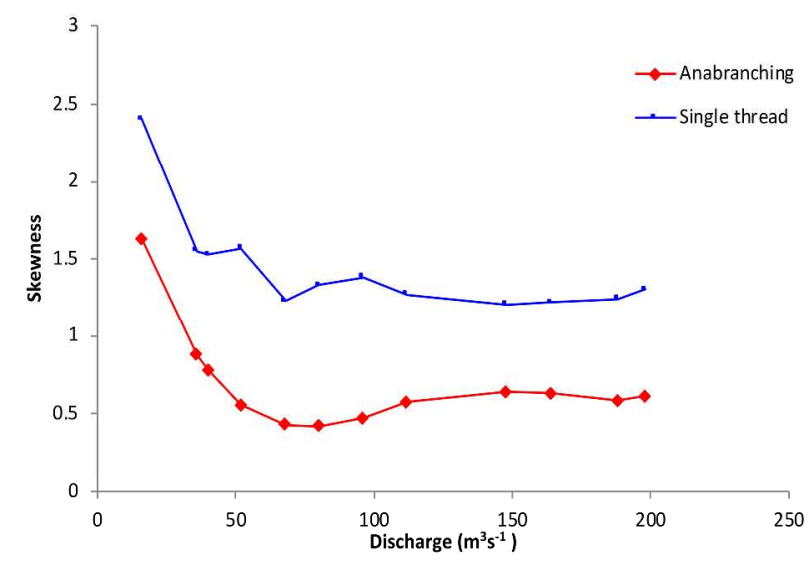

F8

Figure 8.

$629 \times 891 \mathrm{~mm}(200 \times 200$ DPI $)$ 
a)

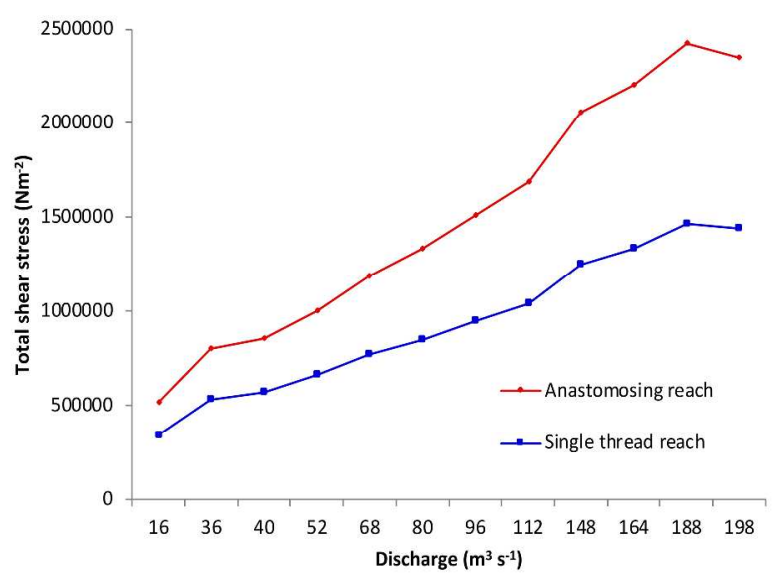

b)

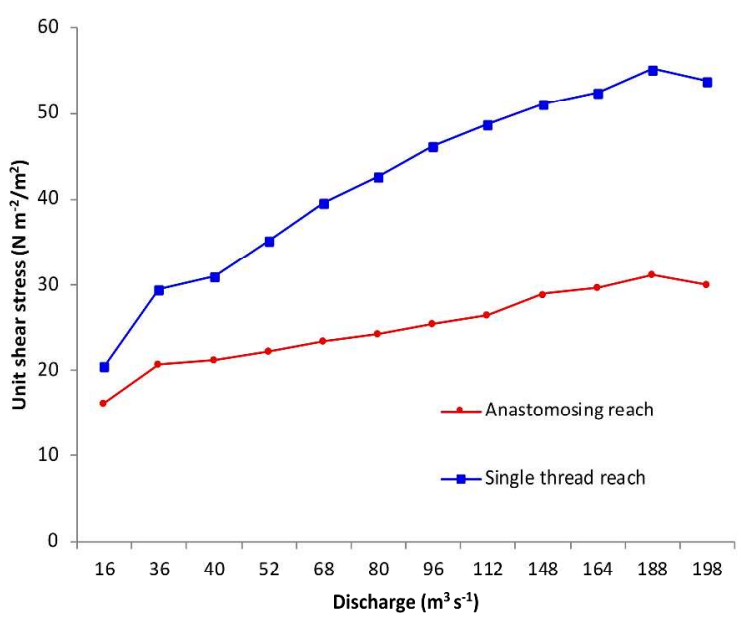

Figure 9 .

$629 \times 891 \mathrm{~mm}(200 \times 200$ DPI $)$

http://mc.manuscriptcentral.com/rra 


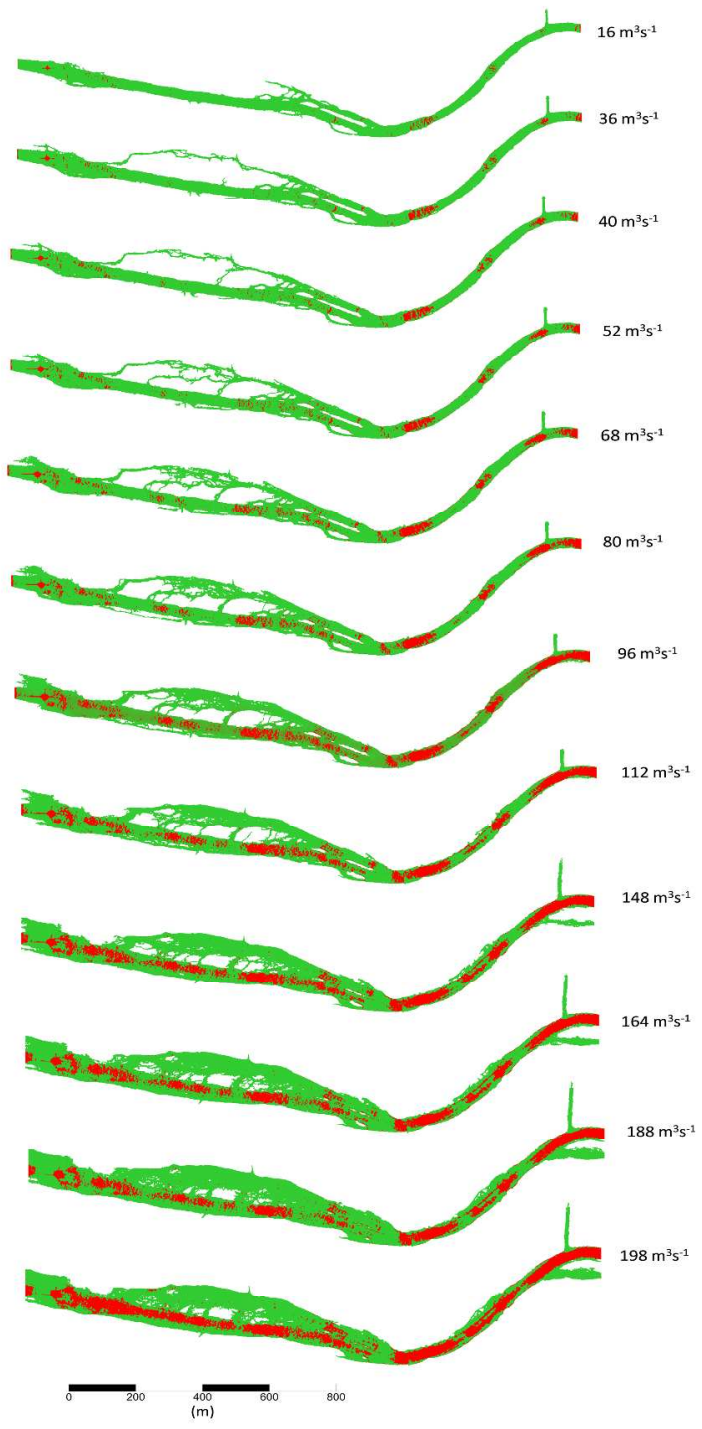

Figure 10.

$629 \times 891 \mathrm{~mm}(200 \times 200$ DPI $)$ 